\title{
BILATERAL DETACHMENT OF THE CHOROID OF UNUSUAL DURATION FOLLOWING CORNEO-SCLERAL TREPHINE*
}

\author{
BY
}

\author{
A. E. P. PARKER \\ MIDDLESBOROUGH
}

Detachment of the choroid following trephining for glaucoma occurs sufficiently often to make it a matter of some importance to ophthalmic surgeons, and any addition to our knowledge of the condition would appear to be of yalue and to warrant putting the following case on record.

Mrs. C., aged 56 years, consulted me first on August 9, 1943, complaining of defective vision of some months duration.

She gave a lengthy history of bad health of staggering complexity and was obviously suffering from myxoedema which it transpired had been overlooked by her medical attendant, but what part this plays in her glaucoma and other ocular troubles I will not venture to say. Vision in the right eye was, with correction, $6 / 18$ and $6 / 12$ in the left. The discs were deeply cupped, the tension one plus, and the fields showed considerable contraction. Figs. 1 and 2.

She was put on miotic treatment and also the myxoedema attended to with great improvement to her general health, the vision improved to $6 / 6$ in each eye, the fields improved slightly and the tension on each occasion it was taken was in the region of only $30 \mathrm{~mm}$. Schiötz.

By January, 1944, in spite of good miosis and a not unduly high tonometer reading, both fields were obviously shrinking, and with the concurrence of Mr. Arkle, of Newcastle, operation was advised.

The right eye was trephined by the classical method on February 19, 1944. The iridectomy was a small complete one, and the flap sutured with a continuous suture.

The anterior chamber reformed in a day or two but was very shallow, and the tension low, and a few days after the operation a typical choroidal detachment was visible in the upper nasal quadrant. As one had seen this often enough before no particular anxiety was felt, but as the weeks and months passed and it changed but little some disquiet was inevitable. A careful search was made for a leak in the flap and over the trephine hole, but the

\footnotetext{
* Received for publication, March 7, 1945.
} 

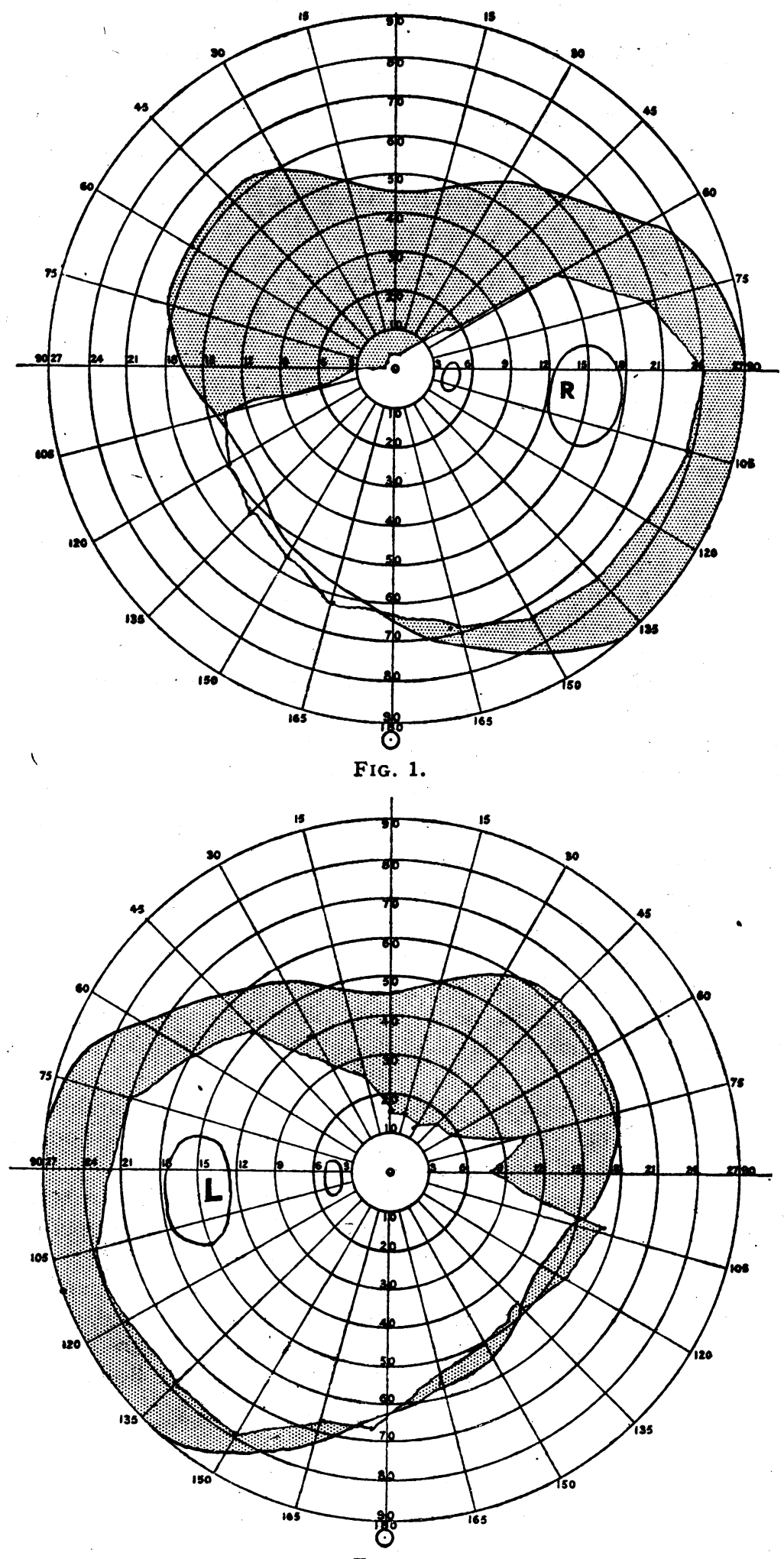

FIG. 2.

Fields before operation, August, 1943. 


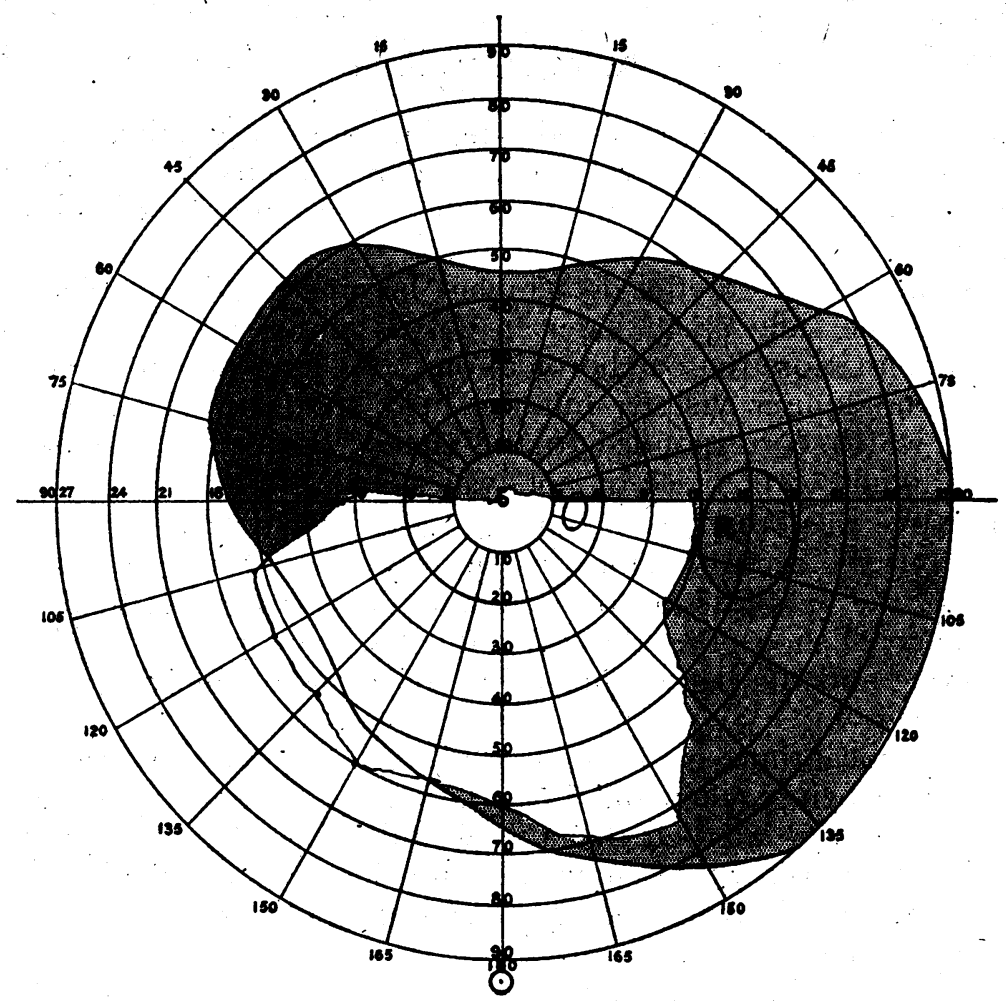

FIG. 3.

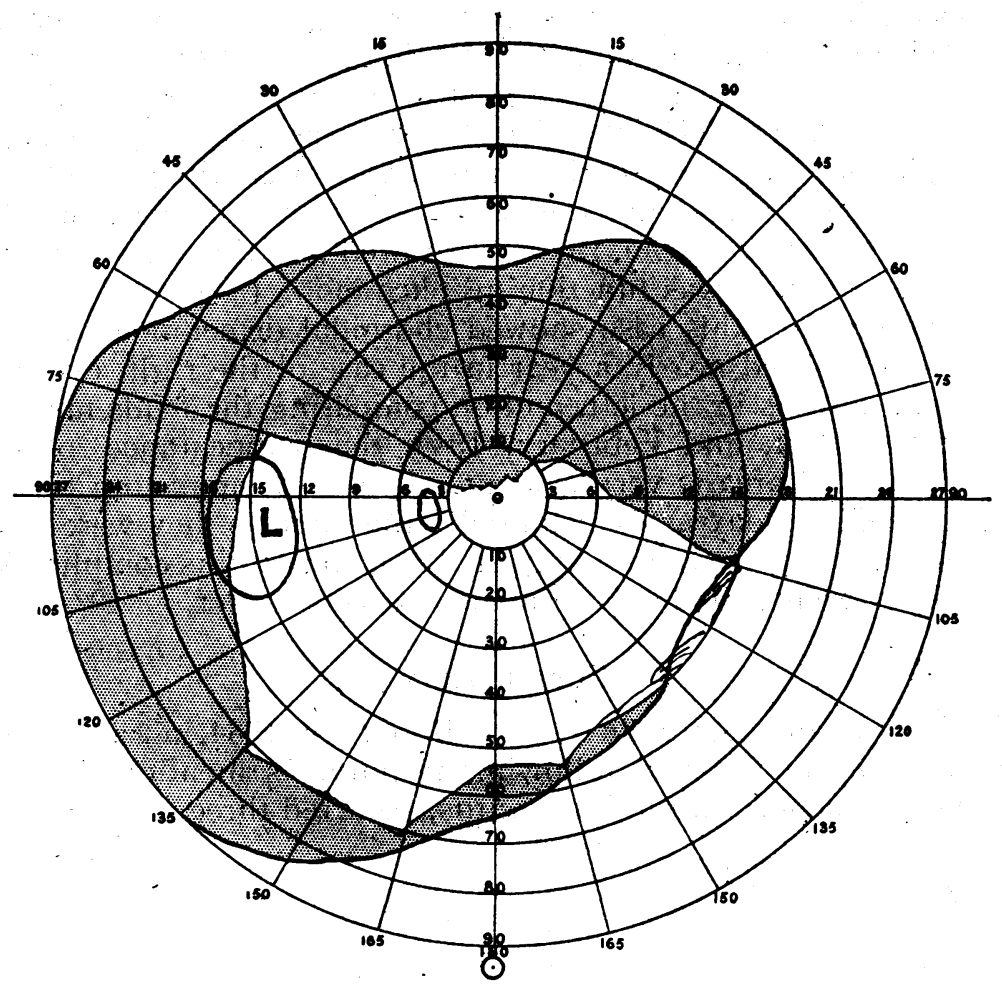

FIG. 4.

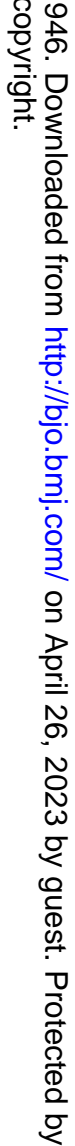

Fields taken with choroidal detachment apparently back in place, November, 1944. 
fluorescein test never revealed one, but the conjunctiva over the hole in the sclera always seemed depressed instead of slightly raised as is usual, and the existence of a tiny leak is highly probable.

As time went on, the detachment became slowly smaller, and at the same time much paler in colour and resembled a retinal detachment more than a choroidal one. At long last in November it was no longer visible, but the field still showed an obvious defect which corresponded to the site of the detachment so the retina, whether in place or not, was not yet functioning. Fig. 3 .

The eye was otherwise behaving well, $T$. Schiötz $15 \mathrm{~mm}$., vision $6 / 18$, but the central vision was slightly affected by the encroachment of the field-loss on to the fixation area. The last field taken February 23 shows that the defect due to the choroidal detachment has gone and the patient herself is conscious of the improvement in it. Fig. 5.

In the meantime, on June 30,1944 , the left eye was trephined, great care being taken on' this occasion to do only a peripheral iridectomy as it was felt that this would be less likely to promote maximum lowering of tension, and lessen the likelihood of choroidal detachment. A $1 \frac{1}{2} \mathrm{~mm}$. trephine was used for each operation incidentally.

Notwithstanding, the left eye showed a typical choroidal detachment, again in the upper nasal quadrant, and the symmetry of the lesion in the two eyes was quite striking. The eye otherwise behaved quite well, and apart from this complication, neither eye did any of the unpleasant things that trephined eyes can do.

By November, 1944, the detachment was no longer visible, although the field showed that it probably was still present to a slight degree, Fig. 4, and the tension was only $12 \mathrm{~mm}$. Schiötz, and on February 23, 1945, the field showed that the retina over the former detachment was functioning once more. Fig. 6.

To summarise, this case showed choroidal detachment in both eyes, which lasted nearly a year in the case of the right eye, and about six months in the left, and on comparing the fields taken in November, 1944, and February, 1945, the reappearance of the lower temporal area is very evident. It is also interesting to note that the fields to-day are substantially the same as they were when the patient was first seen in August, 1943, so that this complication has not apparently had any permanent adverse effect.

\section{Commentary}

In Brown and Bothman's Year Book, for 1934, a case of detachment of the choroid following trephine is mentioned which became reattached within five months, recurred three months later, 


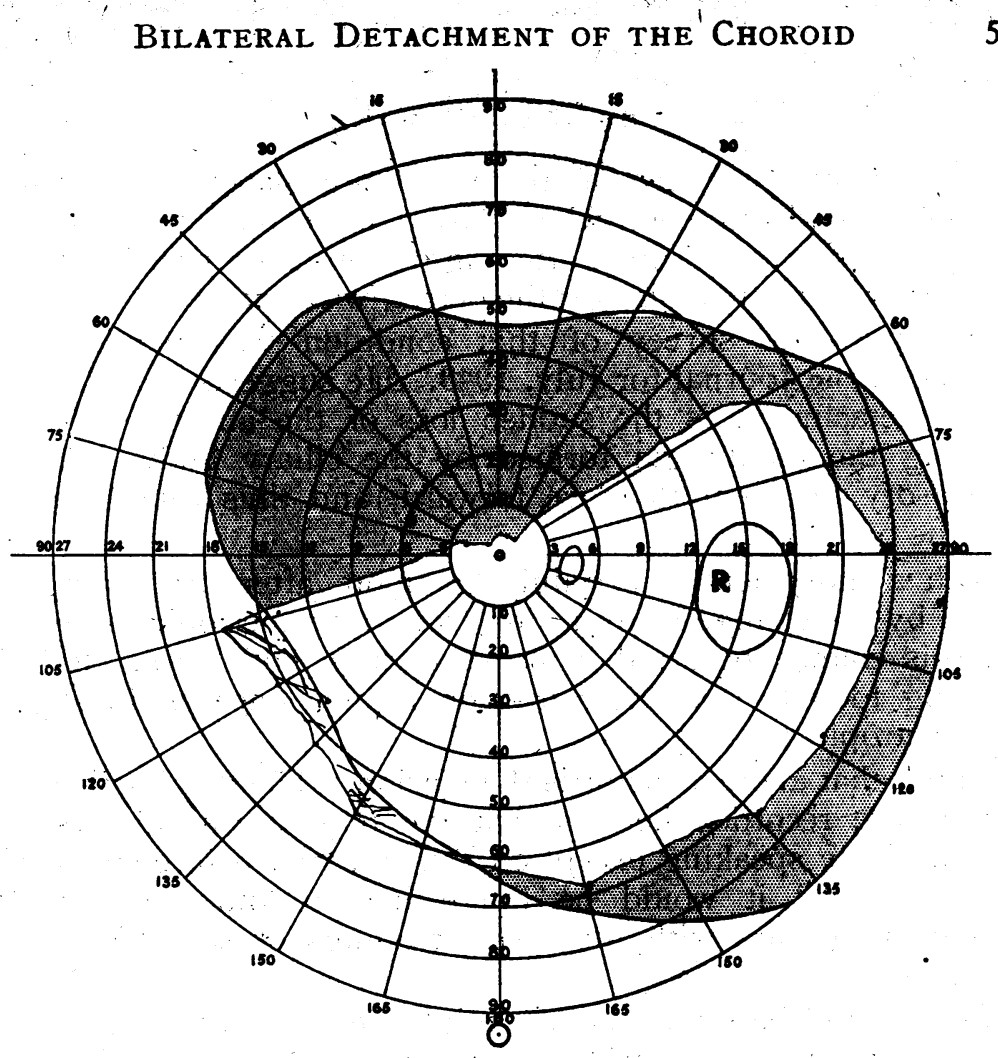

Fig. 5.

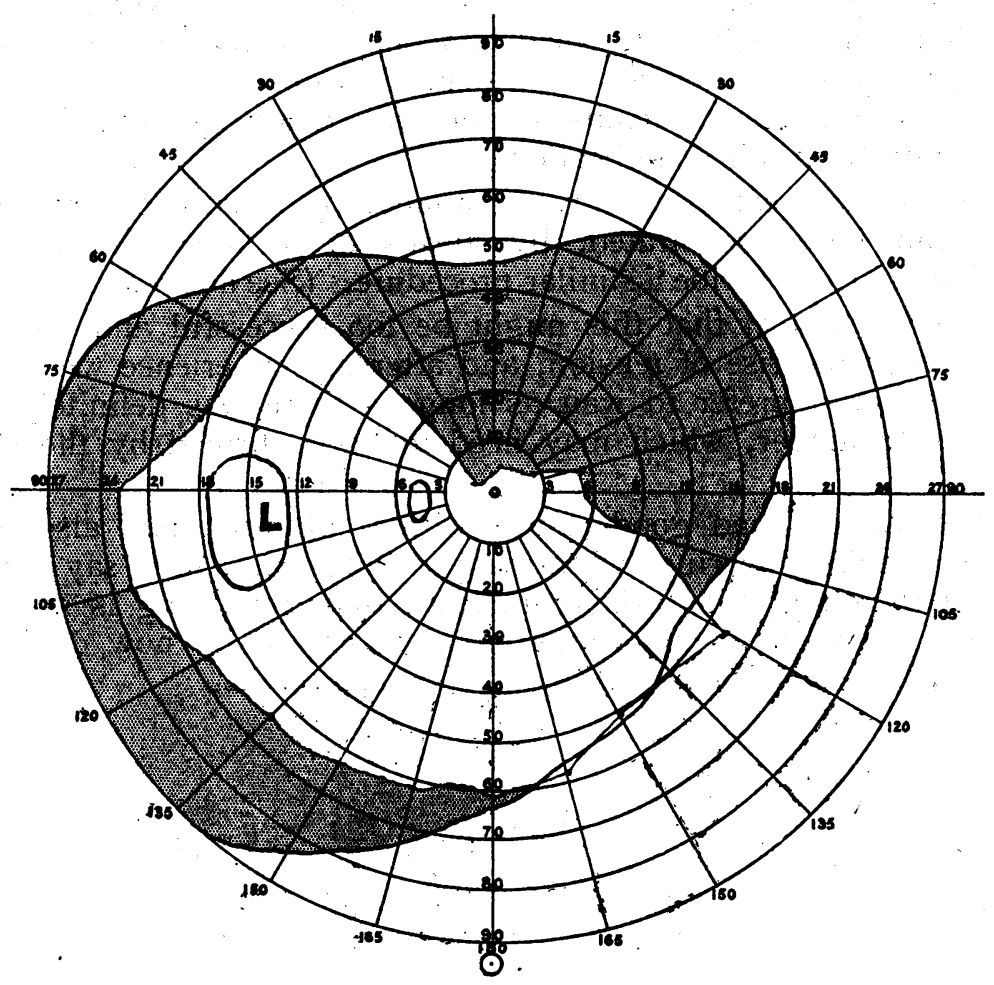

FIG. 6.

Fields showing gain due to reattachment of choroids, February, 1945. 
and was reattached once more two months later. The Editors themselves had only one which lasted more than three months, and that was operated upon after eight months by grafting a piece of superior rectus tendon over the defect, with success.

An up-to-date survey of this condition was published by Rycroft in the Journal for July, 1943. He suggests that the cause of the detachment is the sudden loss of the anterior chamber allowing the diaphragm formed by the ciliary body, lens and suspensory ligament to move forward, and thus causing a tear near the ora.

Such a movement is certainly common after trephining, as shown by the change in refraction from hypermetropia to myopia, and this change occurred in my patient in both eyes. It is interesting to note that the refraction is now once again slightly hypermetropic.

I think that another factor is the tension. The dominant feature of the case recorded here is that the tension was always low, comparatively speaking except on the first visit before she started treatment, and it would be interesting to know if choroidal detachment occurs with tonometer readings of say, $25 \mathrm{~mm}$. or more.

If this could be established, it might be wise to treat glaucoma with lower readings by iridencleisis or cyclodialysis. I have not been able to discover whether these operations are ever followed by choroidal detachment, but it is acknowledged that the tension is often not much lowered by iridencleisis until a period of massage and miotics has elapsed, and this might account for the immunity from this complication.

Rycroft advocates operative treatment by closure of any leak that can be demonstrated, by means of a flap; Brown and Bothman also describe a similar procedure. (See above.)

One would feel that this might be too successful and lead to an undesirable rise of tension, and after my experience with this case I should prefer to wait as long as there was definitely an anterior chamber, which may need to be confirmed by the slitlamp.

We have all had good results with trephining, and also bad ones, and after hearing what many colleagues have to say about the operation it is surprising to learn that trephining is still so widely practised for glaucoma simplex, and I am now doing a series of iridencleisis operations to compare results. 